\title{
AGGRESSIVE DENTIGEROUS CYST IN A 9-YEAR CHILD: A CASE REPORT AND REVIEW OF LITERATURE
}

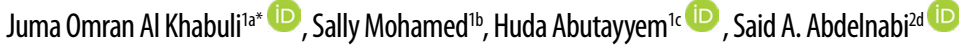 \\ 'RAK College of Dental Sciences, RAK Medical and Health Sciences University, UAE \\ ${ }^{2}$ Al Saqr Hospital, Ras Al Khaimah, UAE \\ aBDS, MDentSci, MFDS RCPS(Glasg), FICD, PhD, Associate Professor, Basic Sciences Department \\ bBDS, MSC, PhD, Assistant Professor, Pediatric Dentistry \\ 'DDS, LDS RCS (Eng), MFDS RCS (Edin), MSc, PhD, Assistant Professor, Orthodontics \\ dBDS, HDD, FDSRCS (Edin), Consultant, Oral and Maxillofacial Surgery
}

\begin{abstract}
DOI: https://doi.org/10.25241/stomaeduj.2019.6(3).art.5
Aim: To report a case of aggressive dentigerous cyst associated with unerupted mandibular $2^{\text {nd }}$ premolar.

Summary: Dentigerous cyst (DC) is a developmental odontogenic cyst, commonly occurs between the $2^{\text {nd }}$ and $3^{\text {rd }}$ decade and is associated with the crown of unerupted tooth. Unless infected, these cysts usually remain asymptomatic. However, they may develop as a result of apical spread of inflammation from primary teeth causing pain, swelling and bone destruction.

A 9-year-old child presented to the pediatric clinic with pain and swelling for 3 weeks. Clinical examination revealed endodontically treated lower left primary $2^{\text {nd }}$ molar with slight mobility. Also, there was an obvious expansion of the buccal plate. The radiographs and CBCT revealed large cystic lesion around the crown of unerupted mandibular left $2^{\text {nd }}$ premolar causing massive destruction of the buccal and lingual plates. The cystic lesion was treated by enucleation and removal of the unerupted $2^{\text {nd }}$ premolar tooth. The histopathology confirmed a diagnosis of dentigerous cyst. The follow-up demonstrated uneventful healing and good prognosis.

\section{Key learning points:}

- It is crucial to follow-up any pulpally treated primary teeth.

- There is a potential Infection spread from infected primary roots to the follicular tissues of permanent teeth that could instigate unexpected pathology.
\end{abstract}

Keywords: Dentigerous Cyst; Enucleation; Marsupialization; Unerupted premolars

\section{Introduction}

Dentigerous cyst (DC) is the most common developmental odontogenic cyst that invariably occurs between the second and third decade and its incidence is second to the radicular cyst [1,2]. The incidence of the DC in young individual is quite low; less than $10 \%$ within the first 10 years of life [3]. The most common site for DC is the mandibular third molar region followed by maxillary canine region. Nevertheless, they may develop in association with unerupted mandibular premolars or supernumerary teeth, with a slight male predominance [4]. The pathogenesis of these cystic lesions is not fully understood. However, it is believed that the accumulation of fluids between the enamel surface and the reduced enamel epithelium (epithelial remnants of tooth-forming organs) leading to separation of the latter and cyst formation. The cyst encloses the crown of the involved tooth and is attached to the cementoenamel junction. DCs are considered developmental in origin, from a tooth follicle; however, there is a strong association between DC development and inflammation spreading from nonvital predecessor teeth [5-7]. Generally, DCs are presented with no symptoms and in many occasions are discovered during routine radiographic examination. Radiographically, they are presented as a unilocular radiolucency around the crown of unerupted tooth with a well-defined sclerotic border. In other instances, they may be symptomatic causing swelling, mobility of teeth, and delay in eruption or pain if it is infected [8]. Diagnosis of DCs is mostly based on the radiographic examination, however, a set of differential diagnosis need to be made in cases with aberrant presentation. Various treatment options of DCs have been advocated, including surgical removal of the cyst and associated tooth, elimination of damage to the affected permanent teeth and marsupialization. Nevertheless, complete removal of the pathological cyst lining along with the involved tooth is preferred to avoid any future recurrence $[3,8,9]$. The aim of this 


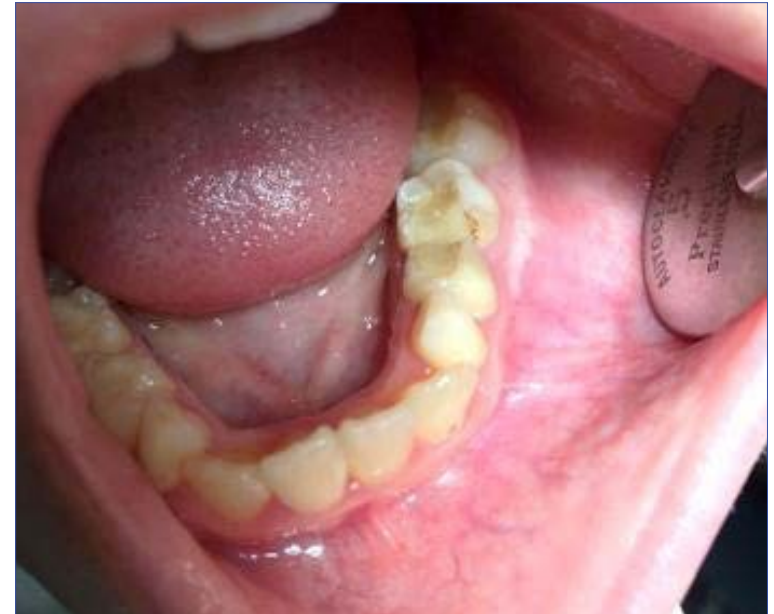

Figure 1. Shows expansion of the buccal cortex.
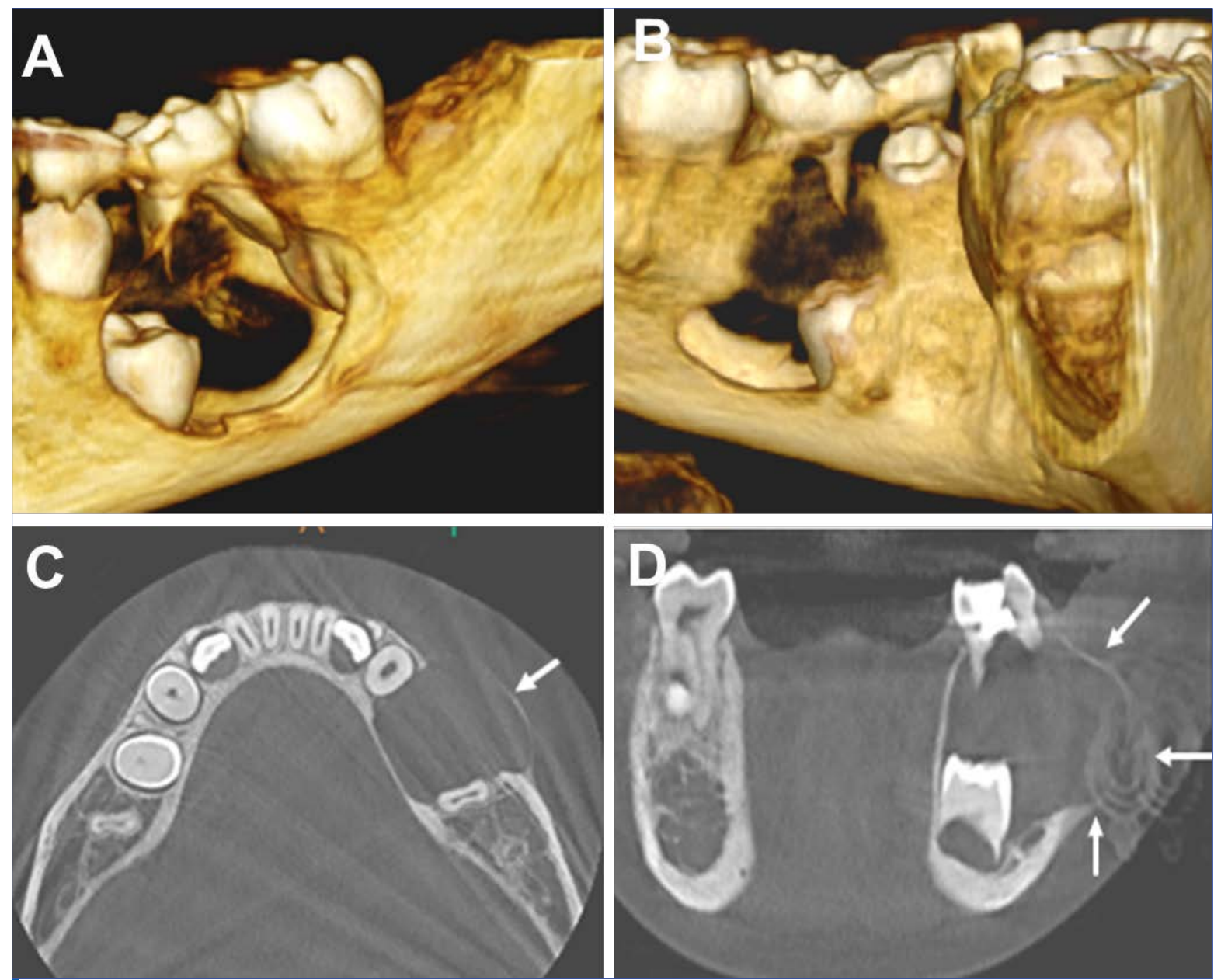

Figure 3. $\mathrm{CBCT}$ images (3D reconstruction) demonstrating massive destruction of the buccal cortex (A) and lingual cortex (B). CBCT axial view (C) and coronal view (D) demonstrating expansion of the buccal cortex and thinning of the lingual cortex.

report is to present a case of aggressive DC involving unerupted lower left second premolar causing massive bone resorption in a young female child.

As a routine procedure, all patients or their guardians attending RAKCODS clinic are required to electronically sign a consent form before launching any treatment procedure. Also, they are aware that any tissues taken from patients or a performed procedure may be utilized for teaching and

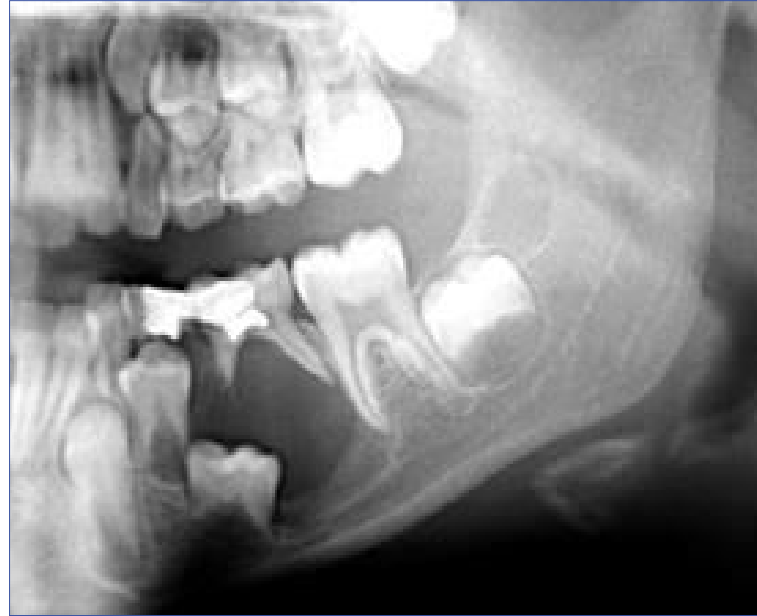

Figure 2. Shows oval-shaped radiolucency and mesial root resorption of the left mandibular $2^{\text {nd }}$ primary molar.

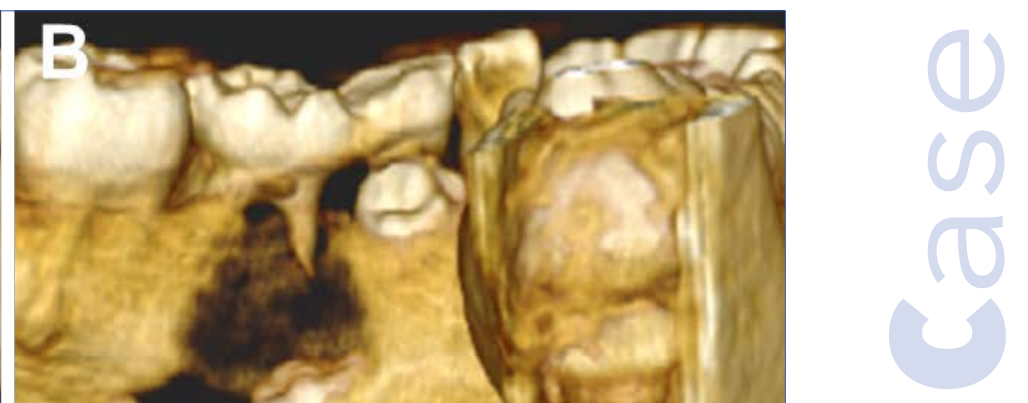

knowledge dissemination without any details that may identify individuals.

\section{Case report}

A 9-year-old female patient presented to the Pediatric Dentistry Department, RAKCODS clinic complaining of severe pain and swelling on the left side of the mandible for the last 4 weeks. On examination, the patient was healthy and the past medical history 


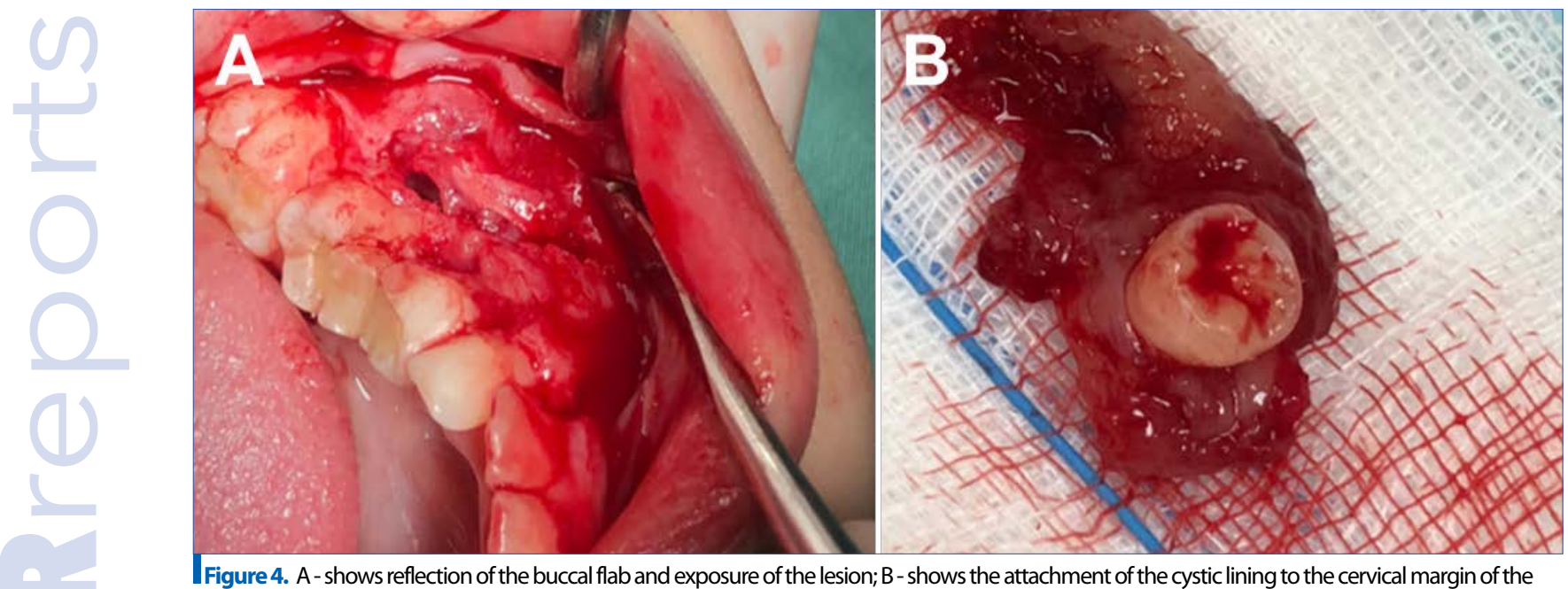
tooth.

revealed no relevant illnesses and the routine blood investigations were within the normal ranges. There was no history of hospitalization or trauma to the jaw. Extra-oral examination revealed a single diffuse swelling on the left side of the face with no sinus or active discharges. Intra-oral examination, showed a hard swelling in the 74,75 regions with obliteration of the buccal vestibule (Fig. 1). The swelling was bony hard with expansion of the buccal cortex, with no evidence of the lingual cortex expansion. The primary left $2^{\text {nd }}$ mandibular molar tooth was nonvisual, showing evidence of pulp therapy and composite filling. The tooth showed slight mobility and the adjacent soft tissues were normal with no signs of inflammation. The permanent first molar (36) was sound and the pulp vitality was not compromised. Orthopantamograph (OPG) revealed an oval-shaped unilocular radiolucency around the developing second premolar with partial sclerotic border. The mesial root of 74 showed resorption with loss of bone in the bifurcation area (Fig. 2). The cone beam computed tomography (CBCT) images revealed thinning of the buccal and lingual cortex (Fig. 3 A-D). Based on the clinical, radiographical and $C B C T$ examination, a provisional diagnosis of dentigerous or bifurcation cyst was made. After consultation with the oral surgeon, it was decided to enucleate the cystic lesion surgically. A surgical incision extending from the distal aspect of 32 to the mesial aspect of 36 was established to expose the involved area. The primary molars $(74 \& 75)$ were removed and the area was explored. The cystic lining of the lesion was found attached to the cervical margin of the 2 nd premolar crown revealing a DC (Fig. 4 A, B). Enucleation of the DC was established with extraction of the unerupted mandibular 2 nd premolar, followed by primary closure of the wound. The whole specimen was kept in $10 \%$ buffered formalin and sent for histopathology examination. The histopathology examination reported a cystic fibrous wall lined by non-keratinized stratified squamous epithelium. Epithelial hyperplasia was noticed in many areas of the lining. The lamina

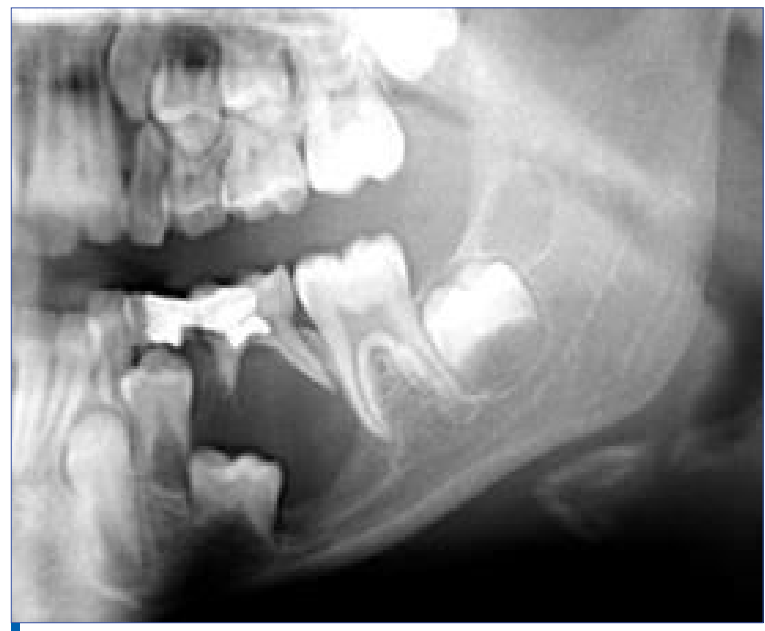

Figure 5. The radiograph demonstrates the regeneration of bone and the temporary space maintainer in place.

propria showed heavy infiltrates of acute and chronic inflammatory cells. These appearances are consistent with DC. The sutures were removed after one week, and the healing was uneventful. Soon after full eruption of 34 crown a space maintainer (band and loop) was fitted in place until further treatment (Fig. 5). Three months radiographic follow up demonstrated progressive bone regeneration filling the cavity and excellent soft tissue healing.

\section{Discussion}

DC is a benign developmental cyst associated with the crown of un-erupted tooth and is the second most common odontogenic cyst [10]. Radiographically, it appears as a solitary, well demarcated radiolucency enclosing a crown of impacted tooth. The hallmark of the cyst is the attachment of the follicular epithelium to the cemento-enamel junction. According to Zhang, et al. [11] the peak incidence is in the second and third decade. In contrast to this finding, Shibata, et al. [12] showed that the age range of discovery of the DC was 9-11 years. In the current case the child age was also 9-year-old. The noticed discrepancy may be attributed to the various studied ethnic groups of population. 
DC is commonly associated with mandibular 3rd mandibular molar [13]. However, in the current case the cyst was associated with the unerupted mandibular $2^{\text {nd }}$ premolar. Although such cases are relatively rare, a few cases have been reported [14]. Shibata et al. [12] studied the occurrence of DCs in association with succedaneous teeth during the transitional dentition phase and reported $77.1 \%$ prevalence in the premolar region. There have been several explanations for the development of DC. The experimental and clinical observations propose two types of DCs; inflammatory and non-inflammatory, instigated by different causes and develop at different stages of tooth development [15]. Three pathways were suggested for histogenesis of the DC. In the first scenario, the developmental DC forms from dental follicle and becomes secondarily infected as a result of a non-vital tooth. The second type occurs when a permanent successor erupts into radicular cyst that forms at apex of a non-vital deciduous resulting into a DC that is extra follicular in origin. Nevertheless, a radicular cyst developing at apex of primary tooth is extremely rare. The third possible cause is due to spread of peri-apical inflammation from a non-vital deciduous tooth to follicle of permanent successor [7].

Two main surgical approaches are usually followed for management of such cystic lesions; either enucleation or marsupialization. Several factors are taken into consideration, such as the size and location of the lesion, the amount of bone loss, integrity of the cystic wall, and its relation to vital structures. Conservative approach, the marsupialization has been advocated for management of DC in children to provide a chance for the unerupted tooth to erupt [16]. Nevertheless, it has a disadvantage that the pathology of the cystic lining is left behind and remains without thorough histopathological

\section{References}

1. Suresh $R$, Janardhanan $M$, Joseph AP, et al. A rare case of dentigerous cyst in a one-year old child: the earliest known reported occurrence. Head Neck Pathol. 2011; 5(2):171-174. [Full text links] [CrossRef] [PubMed] Google Scholar Scopus 2. Al Sheddi MA. Odontogenic cysts. A clinicopathological study. Saudi Med J. 2012; 33(3):304-308.

[PubMed] Google Scholar Scopus

3. Ghandour L, Bahmad HF, Bou-Assi S. Conservative treatment of dentigerous cyst by marsupialization in a young female patient: a case report and review of the literature. Case Rep Dent. 2018;2018:7621363.

[Full text links] [Free PMC Article] [CrossRef] [PubMed] Google Scholar

4. Manjunatha BS, Chikkaramaiah S, Panja P, Koratagere N. Impacted maxillary second premolars: a report of four cases. BMJ Case Rep. 2014;2014:1-4.

[Full text links] [Free PMC Article] [CrossRef] [PubMed] Google $\underline{\text { Scholar Scopus }}$

5. Gupta P, Jawanda MK, Narula R, Singh J. Inflammatory dentigerous cyst mimicking a periapical cyst. J Int Clin Dent Res Organ. 2016;8(1):63-66.

[Full text links] [CrossRef] [PubMed] Google Scholar

6. Srividhya SS, Anand B, Mahesh Kumar P. Dentigerous cyst of inflammatory origin- report of a rare case. WJPPS. 2018;7(9):1064-1069. examination. In our case, enucleation of the cyst including the unerupted tooth approach was chosen. Radiographically, there was substantial bone destruction and examination of the entire cystic tissues was deemed necessary. It was obvious that the cystic lining was attached to neck of the tooth and the histopathology report showed severe inflammation masking the classical microscopic appearance. Three months post-operative follow-up showed uneventful healing. The radiograph showed that the cystic cavity is completely filled with bone. The band and loop space maintainer was provided until further orthodontic treatment is instituted.

\section{Conclusion}

Development of DC in association with an unerupted successor due to inflammatory change at the apex of a deciduous tooth is not uncommon. Although, DCs are asymptomatic, they may cause pain, swelling and massive bone destruction. Therefore, close monitoring of pulpally treated primary molars is crucial to prevent or reduce the potential morbidity associated with the same.

\section{Acknowledgments}

We would like to appreciate the help of the of oral surgery department team in Saqr hospital, RAK for accommodating the case in spite of the busy oral surgery schedule.

\section{Disclosure statement}

The authors report no conflict of interest

\section{Ethical Issue}

The guardian of the patient has signed a consent form in his mother's tongue language with translation and understood that no identifying details would be declared in any form.

7. Benn A, Altini M. Dentigerous cysts of inflammatory origin. A clinicopathologic study. Oral Surg Oral Med Oral Pathol Oral Radiol Endod. 1996;81(2):203-209.

[Full text links] [PubMed] Google Scholar Scopus

8. Şahin O. Conservative management of a dentigerous cyst associated with eruption of teeth in a 7-year-old girl: a case report. J Korean Assoc Oral Maxillofac Surg. 2017; 43(Suppl 1): S1-S5.

[Full text links] [Free PMC Article] [CrossRef] [PubMed] Google Scholar

9. Kirtaniya BC, Sachdev V, Singla A, Sharma AK. Marsupialization: A conservative approach for treating dentigerous cyst in children in the mixed dentition. J Indian Soc Pedod Prev Dent. 2010; 28(3):203-208.

[Full text links] [PubMed] Google Scholar Scopus

10. Villasis-Sarmiento L, Portilla-Robertson J, MelendezOcampo $A$, et al. Prevalence and distribution of odontogenic cysts in a Mexican sample. A 753 cases study. J Clin Exp Dent 2017;9(4):e531-e538.

[Full text links] [CrossRef] [PubMed] Google Scholar Scopus

11. Zhang LL, Yang R, Zhang $L$, et al. Dentigerous cyst: a retrospective clinicopathological analysis of 2082 dentigerous cysts in British Columbia, Canada. Int J Oral Maxillofac Surg. 2010;39(9):878-882.

[Full text links] [CrossRef] [PubMed] Google Scholar Scopus 
12. Shibata Y, Asaumi J, Yanagi Y, et al. Radiographic examination of dentigerous cysts in the transitional dentition. Dentomaxillofac Radiol. 2004;33(1):17-20.

[Full text links] [PubMed] Google Scholar Scopus

13. Terauchi M, Akiya S, Kumagai J, et al. An analysis of dentigerous cysts developed around a mandibular third molar by panoramic radiographs. Dent J (Basel). 2019;7(1).pii:E13.

[Full text links] [Free PMC Article] [CrossRef] [PubMed] Google Scholar Scopus

14. Bhardwaj B, Sharma S, Chitlangia P, et al. Mandibular dentigerous cyst in a 10-year-old child. Int J Clin Pediatr Dent. 2016; 9(3): 281-284. [Full text links] [PubMed] Google Scholar
15. Al-Talabani NG, Smith CJ. Experimental dentigerous cysts and enamel hypoplasia: their possible significance in explaining the pathogenesis of human dentigerous cysts. J Oral Pathol. 1980; 9(2):82-91. [PubMed] Google Scholar Scopus

16. Taysi M, Ozden C, Cankaya AB, et al. Conservative approach to a large dentigerous cyst in an 11-year-old patient. J Istanb Univ Fac Dent. 2016;50(3):51-56.

[Full text links] [CrossRef] [PubMed] Google Scholar

\section{Juma Omran AL KHABULI}

BDS, MDentSci, MFDS RCPS (Glasg), FICD, PhD

Associate Professor, Chair

Basic and Medical Sciences Department

RAK College of Dental Sciences

RAK Medical and Health Sciences University

RAK, UAE

Obtained his BDS from Garyounis University, Libya (1985); MDentSci and PhD from Leeds University, UK (2005); MFDS RCPS (Glasgow) and FICD (2014). Worked as GP for 14 years in various health sectors, Libya before specializing in oral pathology. In 2008 joined RAK College of Dental Sciences, RAKMHSU as associate professor and was one of the founding faculty, and contributed massively in its academic accreditation and curriculum development. His main interest is teaching oral biology, oral pathology and oral medicine. In terms of research, his main research theme is directed towards molecular biology of oral cancer.

\section{Orestions}

\section{A classical dentigerous cyst is classified as:}

口a. Inflammatory;

b. Developmental;

ac. Hereditary;

ad. Reactive.

\section{Diagnosis of dentigerous cyst is mainly based on:}

$\square$ a. Clinical examination;

b. Biopsy;

ac. Radiographic examination;

d. History taken.

\section{Which of the following is a primary differential diagnosis of a dentigerous cyst associated with unerupted premolar tooth?}

Da. Bifurcation cyst;

ab. Radicular cyst;

ac. Paradental cyst;

ad. Periodontal cyst.

\section{A dentigerous cyst can be treated conservatively by:}

$\square$ a. Cyst enucleation;

bb. Surgical extraction;

ac. Orthodontic;

ad. Marsupialization. 